trường bên trong khoang mũi có thể là cản trở trương lực phó giao cảm từ hoạt động co mạch. Cần nhiều nghiên cứu hơn nữa để đánh giá vai trò của cấu trúc thân vách ngăn trong chức năng sinh lý của mũi và vai trò của nó trong gây ra tình trạng nghẹt mũi, những nghiên cứu tiếp theo có thể hướng đến những tiếp cận điều trị mới.

Hiện nay, tại Việt Nam chưa có nghiên cứu nào khảo sát vai trò của cấu trúc này khi xem xét các nguyên nhân gây nghẹt mũi mạn tính. Bên cạnh đó, chưa có nghiên cứu nào đánh giá việc can thiệp cấu trúc thân vách ngăn để điêu trị nghẹt mũi. Chính vì vậy, trong một số trường hợp bệnh nhân sự cải thiện thông thoáng qua mũi sau phẫu thuật không được như kỳ vọng của bản thân họ trước can thiệp.

\section{KẾT LUÂ̂N}

Cấu trúc thân vách ngăn có dạng hình thoi với kích thước $2-3 \mathrm{~cm}$ nằm phía trước cuốn mũi giữa và phía trên cuốn mũi dưới khoảng $2.5 \mathrm{~cm}$ trên sàng mũi. Kích thước đo được chiều rộng trung bình là $13.1 \mathrm{~mm}$ (SD 2.1mm), chiều cao là $17.5 \mathrm{~mm}$ (SD $3.4 \mathrm{~mm}$ ). Khoảng cách từ thân vách ngăn đến các mốc giải phẫu khác trong khoang mũi được ghi nhận trong nghiên cứu này như sau: khoảng cách từ lõi đên sàng mũi là
$21.2 \mathrm{~mm}(\mathrm{SD} 2.1 \mathrm{~mm})$, đến mặt trước xoang bướm là $36 \mathrm{~mm}(\mathrm{SD} 3.5 \mathrm{~mm}$ ) và đến chóp mũi là $40.3 \mathrm{~mm}$ (SD 2.9mm). Khi đánh giá cấu trúc này cần sử dụng thuốc co mạch xịt vào khoang mũi trước khi tiến soi hay chụp khảo sát hình ảnh học. Cần lưu ý cấu trúc này khi bệnh nhân có than phiền nghẹt mũi mạn tính.

\section{TÀI LIÊU THAM KHẢO}

1. Costa DJ, Sanford T, Janney C, Cooper M, Sindwani R. Radiographic and anatomic characterization of the nasal septal swell body. Arch Otolaryngol Head Neck Surg. 2010;136 (11):1107-10. DOI: 10.1001/archoto.2010.201.

2. Setlur J, Goyal P. Relationship between septal body size and septal deviation. Am J Rhinol Allergy. 2011;25(6):397-400. DOI: 10.2500/ajra.2011.25.3671.

3. Wexler D, Braverman I, Amar M. Histology of the nasal septal swell body (sept alturbinat)

4. Elwany S, Salam SA, Soliman A, Medanni A, Talaat E. The septal body revisited. J Laryngol Otol. 2009;123(3):303-8. DOI: 10.1017/ S0022215108003526. Epub 2008 Sep 17.

5. Bojsen-Moller F, Fahrenkrug J. Nasal swellbodies and cyclic changes in the airpassage of the rat and rabbit nose. J Anat. 1971;110(1):25-37.

6. Murat Cem Miman (2006), "Internal Nasal Valve, Revisited With Objective Facts", Otolaryngology and Head and Neck Surgery 134, pp $41-47$.

\title{
KẾT QUẢ PHẪU THUÂTT TẠO HÌNH CÁC TỔN THƯƠNG GÂN DUỖI Ơं VẾT THƯO'NG BÀN TAY
}

\author{
Phạm Kiến Nhật*, Phạm Thị Việt Dung*, Tạ Thị Hồng Thú*
}

\section{TÓM TẮT}

Mục tiêu nhằm mô tả đặc điểm lâm sàng và đánh giá kểt quả điều trị các tổn thương gân duỗi ở vết thương bàn tay. Nghiên cứu gồm 42 bệnh nhhân với 50 ngón tay tổn thương gân duối bàn tay phẫu thuật tại Bệnh viện Đa khoa Xanh Pôn từ 08/2018 đến $05 / 2021$. Kết quả,tuổi trung bình của bệnh nhân là 38.1; độ tuổi lao động (18-60 tuổi) chiếm 39/42 (92.9\%) bệnh nhân; nam giới chiếm tỷ lệ cao với $37 / 42$ bệnh nhân (88.1\%). Tai nạn lao động là nguyên nhân của $2 / 3$ số ca bệnh. Cơ chế tổn thương cắt do vật sắc nhọn chiếm tỉ lệ $88.1 \%(37 / 42 \mathrm{ca})$. Ngón 2 có tỷ lệ tổn thương cao nhất với 18/50 ngón tổn thương $(36 \%)$, vùng tốn thương hay gặp nhất là vùng VI với 13/50 trường hợp (26\%). Phương pháp khâu nối trực

*Trường Đại học Y Hà Nội

Chịu trách nhiệm chính: Phạm Kiến Nhật

Email: nhatpk.25101995@gmail.com

Ngày nhận bài: 9/8/2021

Ngày phản biện khoa học: 27/8/2021

Ngày duyệt bài: 21/9/.2021 tiếp đước áp dung cho 49/50 trường hợp (98\%) với kỹ thuật khâu thay đổi theo vùng và mức độ tổn thương gân,1 trường hợp vết thương mất đoạn gân được tạo hình bằng ghép gân. Kết quả xa đánh giá theo Miller², kết quả tốt chiếm $38 / 50$ ngón tay $(76 \%)$. Kết luân, đặc điểm lâm sàng của các tổn thương gân duỗi bàn tay rất đa dang, cần có sư phân loai chính xác các loaì vết thương tổn thương gân để đưa ra kỹ thuật phục hồi có hiệu quả. Kỹ thuật khâu nối trực tiếp gân đớn giản, phục hồi gân dưỗi đạt kết quảa cao.

Tư khóa: Vết thương gân duỗi bàn tay, khâu gân, ghép gân.

\section{SUMMARY}

\section{THE PLASTIC SURGERY RESULT OF EXTENSOR TENDON INJURIES IN HAND}

This study aims to describe the clinical characteristics and evaluate the treatment results of extensor tendon injuries in hand. The study was carried out on 42 patients with 50 fingers injured in the extensor tendon of the hand at Saint Paul General Hospital from August 2018 to May 2021. Results: The average age of patients is 38.1 with working age (18- 
60 years old) accounts for $92.9 \%$. Man have a high incidence with $37 / 42$ of case, up to $88.1 \%$. Workrelated accidents are the cause of $2 / 3$ of the cases. The mechanism of cutting injury caused by sharp objects accounts for $88.1 \%$. Index finger has the highest rate of injury with $18 / 50$ of cases $(36 \%)$ while the most common lesion is zone VI with $13 / 50$ of cases (26\%). Direct suture method was applied to $98 \%$ of cases with suturing technique varying by region of tendon injury, 1 case of wound with tendon gap was reconstructed by tendon grafting. Further results were assessed according to Miller $^{2}$, good results accounted for $38 / 50$ fingers (76\%). Conclusion: The clinical characteristics of extensor tendon injuries of the hand are very diverse. Therefore, it is necessary to accurately classify the types of tendon injuries in term of providing effective tendon rehabilitation techniques. The technique of direct tendon suture is simple with high results of tendon recovery achievement.

Keywords: hand extensor tendon injury, tendon suture, tendon graft.

\section{I. ĐẶT VẤN ĐỀ}

Vết thương gân duỗi bàn tay là tổn thương thường gặp, chiếm trên $50 \%$ tổn thương gân của bàn tay do các nguyên nhân khác nhau ${ }^{1}$. Trên lâm sàng, hình thái tổn thương gân duỗi bàn tay rất đa dạng, tuy nhiên đây là loại tổn thương thường bị bỏ qua, không được đánh giá đúng và không được điều trị phẫu thuật một cách hợp lý, chính vì vậy di chứng của tổn thương gân duỗi để lại có thể gây tàn phế, giảm khả năng lao động và ảnh hưởng đên tâm lý. Điều trị các tổn thương gân duỗi chủ yếu là phục hồi cấu trúc giải phẩu của gân cũng như hệ thống phụ trợ như dây chằng, bao hoạt dịch. Khâu nối trực tiếp là kỹ thuâtt điều trị chủ yếu trong hầu hết các trường hợp. Trong các tổn thương phức tạp hơn như khuyết phần mềm rộng, mất đoạn gân, ghép gân là một lựa chọn hiệu quả. ở việt Nam, vết thương gân duỗi rất phổ biến, tuy nhiên chưa có nhiều nghiên cứu được công bố về tổn thương gân duỗi ở vết thương bàn tay. Bởi vậy, chúng tôi tiến hành nghiên cứu này với mục tiêu: "Mô tả đặc điểm lâm sàng và đánh giá kết quả điều trị các tôn thương gân duỗi bàn tay".

\section{II. ĐỐI TƯƠNGG VÀ PHƯƠNG PHÁP NGHIÊN CỨU}

2.1. Đối tượng nghiên cứu: Gồm 42 bệnh nhân được chẩn đoán vết thương gân duỗi bàn tay được phẫu thuật tại Khoa Phẩu thuật Tạo hình - Bệnh viện Đa khoa Xanh Pôn từ 08/2018 đến 05/2021.

\subsection{Phương pháp nghiên cứu}

2.2.1. Thiết kế nghiên cứu: Phương pháp nghiên cứu mô tả cắt ngang, hồi cứu kết hợp tiến cứu.

\subsubsection{Qui trình phẫu thuật}

Xử trí ban đầu: Hỏi bệnh và khám lâm sàng tỷ mỷ, phát hiện các tổn thương gân duỗi các mức độ và tổn thương phối hợp; chụp $X Q$ bàn tay thẳng và nghiêng; thuốc: S.A.T 1500UI, kháng sinh Cephalosporin thế hệ 3, giảm đau.

Phấu thuật: Bệnh nhân được gây tê đám rối thần kinh cánh tay hoặc tê tại chố; tư thế nằm ngửa, tay vuông góc với thần người, bàn tay sấp. Garo trên nếp gấp khuỷu $3 \mathrm{~cm}$. Đánh rửa vết thương nhiều lần bằng nước muỗi sinh lý và betadin. Cắt loc mép vết thương (chú ý tiết kiêm da). Phẫu tích tìm gân, nhiêu trường hợp phải rạch da mở rộng dựa trên vết thương có sẵn theo đường zích zắc, đủ rộng để bộc lộ các đầu gân. Phẫu tích tìm đầu gân dựa trên nguyên tắc không làm dập nát thêm đầu gân bằng cách dùng kẹp phẩu tích có mấu hoặc pince để kéo gân, bảo tồn tối đa cấu trúc nuồi gân. Nếu đầu gân duỗi bị dập nát nhiều, chúng tôi xén bỏ một phần để làm gọn đầu gân. Với các vết thương mất đoạn gân duỗi $<5 \mathrm{~mm}$, chúng tôi chỉ định khâu nối gân trực tiếp; ghép gân được chỉ định với các tổn khuyết gân $>=5 \mathrm{~mm}$.

Kỹ thuật khâu gân thay đổi theo vùng tổn thương. Với các vùng phía xa I-IV, gân mảnh và dẹt, chúng tôi thường sử dụng các mũi khâu chũ $X$, khâu mũi vắt. Các vùng phía gần V-VI, gân tròn và dầy hơn, chúng tôi sử dụng các mũi khâu Iõi theo phương pháp Kessler hay Bunnel cải tiến, sau đó tăng cường bằng các mũi khâu Silfverskiold. Khi khâu, ráp hai đầu gân nhe nhàng cho vừa đủ không tạo nên cục sùi ở đường khâu. Sử dụng chỉ liền kim Prolen 4.0 kim tròn, tăng cường bằng chỉ đơn Prolen 5.0 kim tròn. Không khâu $1 / 3$ sau sát nền xương vì có mạch máu nuôi gân duỗi cổ bàn tay.

Đánh giá kết quả xa sau phẩu thuật theo phân loại của Miller ${ }^{2}$ dựa trên tổng phạm vi vận động chủ động.

Bảng 1. Phạm vi vận động chủ động binh thường

\begin{tabular}{|c|c|c|}
\hline Khớp & Gấp (đồ) & Mất duối(độ) \\
\hline Bàn ngón & 85 & 0 \\
\hline Liên đốt ngón gần & 110 & 0 \\
\hline Liên đốt ngón xa & 65 & 0 \\
\hline Tống & 260 & $\mathbf{0}$ \\
\hline
\end{tabular}

Bảng 2. Tiêu chuấn Miller về đánh giá chức năng gân duỗi

\begin{tabular}{|c|c|c|}
\hline Kết quả & $\begin{array}{c}\text { Tống độ mất } \\
\text { duối (độ) }\end{array}$ & $\begin{array}{c}\text { Tống độ mất } \\
\text { gấp(đđộ) }\end{array}$ \\
\hline Tốt & 0 & 0 \\
\hline Khá & $<=10$ & $<=20$ \\
\hline
\end{tabular}


VIETNAM MEDICAL JOURNAL N01 - OCTOBER - 2021

\begin{tabular}{|c|c|c|}
\hline Trung bình & $11-45$ & $21-45$ \\
\hline Kém & $>45$ & $>45$ \\
\hline
\end{tabular}

\section{KẾT QUẢ NGHIÊN CỨU}

Có $37 / 42$ bệnh nhân nam $(88,1 \%)$ và $5 / 42$ bệnh nhân nữ (11,9\%). Tuổi bệnh nhân trong nghiên cứu này thay đổi từ 18 đến 68 tuổi với trung bình là 38.1 tuổi. Nghề nghiệp của bệnh nhân rất đa dạng, nhưng chủ yếu gặp ở nhóm lao động phổ thông với 36/42 bệnh nhân (85.7\%).

Tai nạn lao động là nguyên nhân chính, chiếm tới $2 / 3$ số ca. Chấn thương do dụng cụ sắc nhọn là cơ chế chính gây ra các tổn thương gân gặp ở 37/42 bệnh nhân (88.1\%). Tay thuận là vị trí tổn thương chủ yếu với 25/42 (59.5\%) số ca. 35/42 bệnh nhân (83.3\%) tổn thương gân duỗi của 1 ngón tay, $7 / 42$ bệnh nhân (16.7\%) bị nhiều hơn 1 ngón.

Ngón tay bị thương phổ biến nhất trong nghiên cứu này là ngón 2 với $18 / 50$ ngón tổn thương (36\%), theo sau là ngón 3 với $11 / 50$ ngón tay $(22 \%)$. Vùng VI là vùng bị tổn thương phổ biến nhất, chiếm 13/50 (26\%) số ca bệnh.

Bảng 3. Phân bố vị trí tôn thương gân theo ngón tay

\begin{tabular}{|c|c|c|c|c|c|}
\hline $\begin{array}{l}\text { Số ngón } \\
\text { tốn } \\
\text { thương }\end{array}$ & $\begin{array}{l}\text { Số } \\
\text { nh }\end{array}$ & êlnh & $\begin{array}{l}\text { Vị trí } \\
\text { ngón }\end{array}$ & $\begin{array}{l}\text { Tổng } \\
\text { số } \\
\text { ngón }\end{array}$ & $\begin{array}{l}\text { Tỷ lệ } \\
\text { BN } \\
(\%)\end{array}$ \\
\hline & & 6 & Ngón 1 & & 12 \\
\hline & & 15 & Ngón 2 & & 30 \\
\hline Moút & & 8 & Ngón 3 & 35 & 16 \\
\hline & 35 & 3 & Ngón 4 & & 6 \\
\hline & & 3 & Ngón 5 & & 6 \\
\hline & & 1 & Ngón 1,2 & & \\
\hline $\begin{array}{l}\text { Hal } \\
\text { nqón }\end{array}$ & 6 & 2 & Ngón 2,3 & 12 & 24 \\
\hline & & 3 & Ngón 4,5 & & \\
\hline $\begin{array}{c}\text { Ba ngón } \\
\text { Tống }\end{array}$ & & & Ngón 3,4,5 & 3 & $\begin{array}{c}6 \\
100\end{array}$ \\
\hline Tong & & & & 50 & \\
\hline
\end{tabular}

Về phương pháp điều trị, khâu nối gân trực tiếp được chỉ định ở 49/50 trường hợp chiểm 98\%. Một trường hợp dập nát, mất đoạn gân tới $5 \mathrm{~mm}$, chúng tôi đã chỉ định ghép gân tự do với mảnh ghép lấy tữ phần trung tâm gân duỗi vùng IV cùng ngón.

Về kết quả gần: thời gian nằm viện trung bình là 3.7 ngày. Không có ngón tay nào đứt lại gân sau mổ.

Các bệnh nhân được theo dõi trong thời gian trung bình 12,5 tháng (6-24 tháng). Kết quả cuối cùng được đánh giá theo phân loại của Miller dựa trên tổng phạm vi vận động chủ động. Kết quả "Tốt" được thấy trong $50 \%$ trường hợp, kết quả "Khá" trong $26 \%$, kết quả "Trung bình" trong $20 \%$ và kết quả "Kém" gặp ở 4\% trường hợp.
Bảng 4. Kêt quả xa theo vùng tôn thương gân duổi (N=50)

\begin{tabular}{|c|c|c|c|c|}
\hline Vùng & Tốt & Khá & Trung bình & Kém \\
\hline I & 3 & 1 & 1 & 0 \\
\hline II & 4 & 0 & 3 & 0 \\
\hline III & 1 & 4 & 3 & 1 \\
\hline IV & 2 & 3 & 0 & 1 \\
\hline V & 8 & 1 & 1 & 0 \\
\hline VI & 7 & 4 & 2 & 0 \\
\hline Tống & $\mathbf{2 5}$ & $\mathbf{1 3}$ & $\mathbf{1 0}$ & $\mathbf{2}$ \\
\hline Tỷ lệ \% & $\mathbf{5 0}$ & $\mathbf{2 6}$ & $\mathbf{2 0}$ & $\mathbf{4}$ \\
\hline
\end{tabular}

Vùng $\mathrm{V}$ là vùng có kết quả cuối cùng sau phẫu thuâtt khả quan nhất, với các kết quả "Tốt" và "Khá" chiếm tới $9 / 10$ trường hợp $(90 \%)$ theo sau là vùng VI với 11/13 trường hợp (84.6\%). Trong khi đó vùng III có kết quả sau cùng kém nhất với 4/9 ca (44.4\%) có kết quả "Trung bình" và "Kém".

Bảng 5. Kêt quả xa theo ngón tôn thương gân duối $(N=50)$

\begin{tabular}{|c|c|c|c|c|}
\hline $\begin{array}{c}\text { Gân duôi } \\
\text { nối }\end{array}$ & Tốt & Khá & $\begin{array}{c}\text { Trung } \\
\text { bình }\end{array}$ & Kém \\
\hline Ngón 1 & 4 & 2 & 1 & 0 \\
\hline Ngón 2 & 10 & 4 & 3 & 1 \\
\hline Ngón 3 & 3 & 3 & 4 & 1 \\
\hline Ngón 4 & 3 & 3 & 1 & 0 \\
\hline Ngón 5 & 5 & 1 & 1 & 0 \\
\hline Tống & $\mathbf{2 5}$ & $\mathbf{1 3}$ & $\mathbf{1 0}$ & $\mathbf{2}$ \\
\hline Tỷ lệ (\%) & 50 & 26 & 20 & 4 \\
\hline
\end{tabular}

Trong nghiên cứu này, kết quả "Tốt" gặp thường xuyên hơn ở ngón $V$ với $5 / 7$ ngón tay chiếm $71.4 \%$; theo sau là ngón I với $4 / 7$ ngón đat $57 \%$; trong khi chỉ $3 / 11$ ngón III có kết quả "Tốt". Các kết quả "Trung bình" và "Kém" cũng được quan sát thấy nhiều nhất tại ngón III với 5/11 ngón, chiếm $45.4 \%$ ca bệnh.

\section{BÀN LUÂN}

Việc so sánh các nghiên cứu về sửa chữa gân duỗi bị hạn chế bởi tính không đồng nhất của bệnh nhân, kỹ thuật và phác đồ điều trị sau phẫu thuật ${ }^{3}$. Việc loại trừ các chấn thương bàn tay bị dập nát lớn và các trường hợp có chấn thương gân gấp liên quan cho phép tập trung vào tác động của chấn thương gân duối đối với chức năng cuối cùng của bàn tay.

Trong nghiên cứu này, tuổi trung bình các bệnh nhân là 38.1, dao động từ 18 đến 68 tuổi, tương đồng với nghiên cứu của các tác giả khác như Dominic ${ }^{4}$, tuổi trung bình là 32.4 và Mohammed ${ }^{5}$, tuổi trung bình 30.5 (4-52 tuổi). Newport et $a^{6}{ }^{6}$ ghi nhận tuổi trung bình của bệnh nhân trong nghiên cứu của mình nhưng khổng coi đó là yếu tố ảnh hưởng đáng kể đến kết quả cuối cùng. Trong nghiên cứu này, kết quả theo 
nhóm tuổi cũng khác biệt không có ý nghĩa thống kê.

Báo cáo phân bố giới tính khác nhau trong các tài liệu. Trong nghiên cứu này, có 37 bệnh nhân nam đại diện cho $88.1 \%$ trường hợp và 5 bệnh nhân nữ đại diện cho $11.9 \%$ trường hợp. Các nghiên cứu xem xét sự phân bố giới tính đã ghi nhận nam giới là giới tính bị ảnh hưởng nhiều nhất với các tổn thương gân duỗi; có thể tới 100\% như trong nghiên cứu Khachaba7 hoặc $81,25 \%$ như trong nghiên cứu của Fitoussi et al ${ }^{8}$. Về mặt logic, tỷ lệ bệnh nhân nam cao có thể lý giải do tính chất khó khăn của các hoạt động mà nam giới tham gia nhiêuu hơn.

Về đặc điểm thương tổn, tay thuận là vị trí thường gặp hơn của các tổn thương gân duỗi. Trong nghiên cứu này, tỷ lệ gặp các tổn thương gân duỗi trên bàn tay thuận là $59.5 \%$, kết quả này tương đồng với các nghiên cứu của Mohammed $^{5}$ với $56,7 \%$ và Dominic ${ }^{4}$ với $60 \%$. Điều này có thể được lí giải bởi sự tham gia nhiều hơn của bàn tay thuân trong sinh hoạt và lao động làm tăng nguy cơ tổn thương do tai nạn.

Báo cáo về số ngón tay tổn thương gân duỗi trong các nghiên cứu có sự tương đồng. 83.3\% ca bệnh trong nghiên cứu của chúng tôi tổn thương gân quan sát thấy ở chỉ 1 ngón tay; tỷ lệ này ở nghiên cứu của Mohammed ${ }^{5}$ là $70 \%$. Tần suất thương tổn gân duỗi khác nhau giữa các ngón. Trong nghiên cứu này, ngón II có tỷ lệ cao nhất $(38 \%)$, theo sau là ngón III $(22 \%)$, kết quả này tương đồng với nghiên cứu của Mohammed ${ }^{5}$ với tỷ lệ tổn thương ở ngón II và III lên tới 58\%; khác biệt với kết quả trong nghiên cứu của Dominic ${ }^{4}$ với ngón I là ngón có tỷ lệ tổn thương gân cao nhất (25.7\%).

Có nhiều yếu tố khác nhau có thể ảnh hưởng đến kết quả cuối cùng trong đó kĩ thuật khâu gân đóng vai trò chủ đạo; điều này được hầu hết các tác giả nhấn mạnh trong các nghiên cứu của mình như Mohammed ${ }^{5}$, Newport et $a^{6}$. Kỹ thuật khâu lý tưởng phải cho phép gân trượt dể dàng, hạn chế tối đa sự dính và ngắn gân, dễ thực hiện nhưng phải đủ chắc để cho phép vận động sớm 5 . Kỹ thuâat khâu gân thay đổi tùy thuộc vào đặc điểm tổn thương gân. Gân duỗi bàn tay có cấu trúc mỏng và dẹt hơn gân gấp và nằm sát cấu trúc xương. Điêuu này khiến chúng rất dễ bị dính và ngắn lại trong quá trình sửa chữa, làm giảm đáng kể pham vi chuyển đông khớp. Không giống như gẩn gấp có khả năng huy động để vượt qua khoảng trống lên đến $1 \mathrm{~cm}$; ở gân duỗi, đăc biệt các vùng $I-V$, ngắn gân $1 \mathrm{~mm}$ ở có thể gẩy ra mất duỗi lên tới 20 độ5. Trong nghiên cứu, có tới 25/50 (50\%) ngón tay có vết thương phần mềm dập nát, nham nhởđòi hỏi phải cắt lọc bớt đầu gân trước khi khâu, làm tăng nguy cơ dính và ngắn gân, 1 trường hợp trong số đó có tổn thương dập nát, mất đoạn gân tới $5 \mathrm{~mm}$ chúng tôi phải chỉ định ghép gân tự do với mảnh ghép lấy từ phần trung tâm gân duỗi vùng IV cùng ngón. Đó có thể là lý do kết quả xa về chức năng của nhóm bệnh nhân này không khả quan với chỉ $17 / 25$ ngón tay cho kết quả xa về chức năng ở mức tốt (68\%) làm kết quả chức năng chung của tất cả bệnh nhân trong nghiên cứu chì đạt mức $76 \%$.

Vị trí tổn thương gân cũng ảnh hưởng tới thay đổi kỹ thuật khâu gân. Hình thái của gân duối thay đổi từ mỏng và dẹt ở phần xa đến tròn và dày hơn ở phần gần. Trong nghiên cứu này, chúng tôi sử dụng các mũi khâu chữ $X$, khâu mũi vắt cho các vùng tổn thương phía xa (I-IV); với vùng phía gần (V-VI), chúng tôi sử dụng các mũi khâu Iõi theo phương pháp Kessler hay Bunnel cải tiến, sau đó tăng cường bằng các mũi khâu Silfverskiold. Kết quả gần cho thấy không có trường hợp nào đứt lại gân sau mổ.

Mối quan hệ giữa vùng tổn thương và kết quả cũng là một khái niệm quan trọng. Gân duỗi vùng mu ngón tay (I-IV) mỏng dẹt và nằm rất nông, nằm sát da và xương đốt ngón và tạo với 2 cấu trúc đó nhiều mối liên kết, điều đó dẫn đến việc sửa chữa gân duỗi tại vùng này có thể dẫn đến làm ngắn gân và có nguy cơ dính gân cao hơn so với gân duỗi vùng mu bàn tay (V-VI). Trong nghiên cứu của chúng tôi, các vùng $V$ và VI có kết quả sau cùng tốt hơn các vùng phía xa I-IV. Điều này là do thực tế rằng gân duối trong vùng III có cấu trúc phức tạp, nơi các cấu trúc bên trong và bên ngoài của hệ thống gân duỗi được kết hợp với nhau. Sự kêt dính hình thành trên khớp liên đốt ngón gần của mặt mu dẫn đến hạn chế sự gấp hoặc mất khả năng duỗi của ngón tay. Trong nghiên cứu này, vùng có kết quả kém nhất là vùng III, kết quả "Trung bình" và "Kém" chiếm tới $44.4 \%$, phù hợp với các nghiên cứu khác của Khachaba ${ }^{7}$ và Fitoussi et $a^{8}$.

\section{KẾT LUÂN}

Thương tổn gân duỗi bàn tay thường gặp ở nam giới; chủ yếu trong độ tuổi lao động; gặp nhiều hơn ở tay thuận. Vị trí tổn thương hay gặp nhất là ngón 2 và vùng tổn thương có tỷ lệ cao nhất là vùng VI. Hầu hết các tổn thương gân duỗi chỉ cần khâu nối trực tiếp đã có thể cho hiệu quả phục hồi chức năng tốt.

\section{TÀI LIỆU THAM KHẢO}


1. Doyle JR (1999). Extensor tendons acute injuries. In: Green DP, Hotchkiss R, Pederson WC eds Greeen's operative hand surgery. 4th ed. Philadelphia: Churchill Livingstone;1441-1462.

2. Miller H (1942). Repair of severed tendons of the hand and wrist. Surg Gynecol Obstet; $75: 693-698$.

3. Eaton RG (1969). The extensor mechanism of the fingers. Bull Hosp Joint Dis; 30 :39-47.

4. Dominic Patillo et al (2012). Open extensor tendon injuries: an epidemiologic study. Hand Surg;17(1):37-42.
5. Mohammed Ahmed Kadah (2015). Evaluation of the results of management of acute extensor tendon injuries of the hand. Menoufia Medical Journal;28(1):149-153.

6. Newport ML et al (1990). Long term results of extensor tendon repair. J Hand Surg; 15A, 961-966.

7. Khachaba YA (2008). Evaluation of the outcome after repair of injuries to the extensor tendons of the hand, [MScs thesis]. Cairo: Cairo University; 90-133.

8. Fitoussi $\mathbf{F}$ at al (2007). Extensor tendon injuries in children. J Pediatr Orthoop; 27: 863-866.

\section{ĐĂC ĐIỂM LÂM SÀNG, CÂN LÂM SÀNG VÀ HİNH ẢNH CộNG HƯỞNG TỪ Ở BÊNNH NHÂN TĂNG SINH LÀNH TÍNHTUYẾN TIỀN LIÊTT ĐƯợC CAN THIỆP NÚT ĐộNG MẠCH TUYẾN TIỀN LIỆT}

\section{TÓM TĂT}

Mục tiêu: Mô tả đặc điểm lâm sàng, cận lâm sàng và hình ảnh cộng hưởing từ của bệnh nhân tăng sinh lành tính tuyến tiền liêt được can thiêp nút đônng mach tuyến tiền liệt. Đối tượng và phương pháp:Nghiên cứu hồi cứu được thươ hiển trên $66 \mathrm{BN}$ tăng sinh lành tính tiền liệt tuyến tuyến được can thiệp nút động mạch tuyến tiên liệt tại BV Hữu Nghị từ 05/2015 đến 06/2019, mô tả đặc điểm lâm sàng, cận lâm sàng và hình ảnh công hưởng từ trước can thiệ. Kết quả: Từ tháng 05/2015 đến tháng 06/2019, có 66 BN với tuổi trung bình $73,58 \pm 7,9$ tuổi,thể tích trung bình tuyến tiền liệt $62,8 \pm 29,86 \mathrm{~mL}$, nồng độ PSA trung bình $10 \pm 18,57 \mathrm{ng} / \mathrm{mL}$. Toàn bộ các BN đều có hội chứng đường tiểu dưới mức độ nặng (IPSS > 20 điểm), trong đó chiếm tỉ lệ cao nhất là phố điểm >30 với $59,1 \%$; Tiểu rắt là triêuu chứng có tần suất lớn nhất với tỉ lệ $92,4 \%$, tiếp đến là các triệu chứng tiểu ngắt quãng $72,7 \%$ và tiểu yếu $66,7 \%$. Dạng biến đổi hình thái tuyến tiền liệt trên cộng hưởng từ thường gặp nhất theo phân loại của Wasserman là loại $1(28,8 \%)$ và loại $3(37,9 \%)$, không có trường hợp nào loại 4 . Tăng sinh lành tính tuyến tiền liệt có lôi vào lòng bàng quang chủ yếu gặp ở loại 5 với 14/23 trường hợp. Trong số các trướng hợp có lồi vào lòng bàng quang, lồi đô̂ 3 (>10mm) chiểm đa số với tỉ lệ $69,6 \%$. Kết luân: Chọn bệnh nhân can thiệp nút động mạch tuyến tiền liệt phụ thuộc nhiều yếu tố bao gồm cả triệu chứng lâm sàng và xét nghiệm sinh hóa, hình ảnh với mục đích đánh giá chính xác tình trạng bệnh. Trong đó, cộng hưởng từ là phương pháp chẩn đoán hình

${ }^{1}$ Bệnh viện Hữu Nghi

${ }^{2}$ Trung tâm Chẩn đoán hình ảnh-Bệnh viện đa khoa Tâm Anh

Chịu trách nhiệm chính: Trịnh Tú Tâm

Email: tutambvhn@gmail.com

Ngày nhận bài: 7/8/2021

Ngày phản biên khoa hoc: 7/9/2021

Ngày duyệt bài 22/9/2021
Trịnh Tú Tâm ${ }^{1}$, Nguyễn Hoàng Thịnh ${ }^{1}$, Nguyễn Quốc Dũng ${ }^{1}$, Nguyễn Xuân Hiền ${ }^{2}$

ảnh giá trị để đánh giá thể tích, hình thái, tính chất nhu mô tuyến trước can thiệp.

\section{SUMMARY}

\section{CLINICAL, PARACLINICAL AND MAGNETIC \\ RESONANCE IMAGING FEATURES $\backslash$ IN \\ PATIENTS WITH BENIGN PROSTATIC HYPERPLASIA UNDERGOING PROSTATIC ARTERY EMBOLIZATION}

Objectives: To describe the clinical, paraclinical and magnetic resonance imaging characteristics of patients with benign prostatic hyperplasia undergoing prostatic artery embolization. Subjects and research methods: A retrospective study was performed on 66 patients with benign prostatic hyperplasia who underwent prostatic artery embolectomy at Huu Nghi Hospital from May 2015 to June 2019. Describe clinical, paraclinical and magnetic resonance images before intervention. Results: From May 2015 to June 2019, there were 66 patients with mean age $73.58 \pm 7.9$ years, mean prostate volume $62.8 \pm 29.86 \mathrm{~mL}$, mean PSA concentration $10 \pm 18.57$ $\mathrm{ng} / \mathrm{mL}$. All patients had severe lower urinary tract syndrome (IPSS > 20 points), of which the highest percentage was score > 30 with 59.1\%; Urinary incontinence is the symptom with the highest frequency with the rate of $92.4 \%$, followed by the symptoms of intermittent urination $72.7 \%$ and weak urine stream $66.7 \%$. The most common form of prostate morphological change on magnetic resonance imaging according to Wasserman's classification was type $1(28.8 \%)$ and type $3(37.9 \%)$, none of which were classified as type 4 . Benign prostatic hyperplasia with protrusion into the bladder was mainly seen in type 5 with $14 / 23$ cases. Among the cases with protrusion into the bladder, grade $3(>10 \mathrm{~mm})$ accounted for the majority with the rate of $69.6 \%$. Conclusion: Selection of patients for prostatic artery embolization depends on many factors including clinical symptoms and biochemical as well as 